\title{
A Sensitive Period for the Maintenance of Emotionality in Mongolian Gerbils
}

\author{
Mertice M. Clark and Bennett G. Galef, Jr. \\ McMaster University, Hamilton, Canada
}

\begin{abstract}
Gerbils reared and continuously housed in cages providing access to shelter respond throughout life to sudden visual stimulation by fleeing, hiding, and foot thumping. Gerbils reared and housed in cages lacking shelter exhibited this pattern of response to stimulation at 26 and 31 days of age but not at greater ages. During a limited period (Days 30-60 after birth) experience with shelter was sufficient to maintain reactivity to stimulation, but similar experience with shelter at 21,90 , or 126 days of age was not sufficient to do so. These findings indicate (a) that shelter experience is a necessary condition for the maintenance of enhanced reactivity to stimulation but not for its development and (b) that gerbils are not equally sensitive to shelter experience throughout life.
\end{abstract}

In their natural environment, Mongolian gerbils (Meriones unguiculatus) live and rear their young in burrow systems which provide protection from predators, moderate the effects of extreme temperatures, and provide a site for the storage of food (Hamaganov, 1954; Leont'ev, 1954, 1957, 1962; Tanimoto, 1943; Thiessen \& Yahr, 1977, p. 64; Won, 1961). Recent evidence suggests that in addition to providing gerbils with a secure home site, life in a burrow system may also have profound effects on the behavioral development of burrow residents (Clark, 1974; Clark \& Galef, 1977; Thiessen, 1973).

We have found that gerbils of a domesticated strain reared either in tunnel systems constructed by their parents or in laboratory cages providing access to shelter flee in response to sudden visual stimulation, are difficult to capture and handle, bite frequently, and are susceptible to epileptiform seizures when disturbed. Gerbils of the same strain reared in cages lacking shelter tend to approach a suddenly presented vi-

The research reported here was supported by $\mathrm{Na}$ tional Research Council of Canada Grant AO-307 and a McMaster University Research Board grant to the second author. The first author was supported by a National Research Council of Canada postdoctoral fellowship during a portion of the time when this research was in progress.

Requests for reprints should be sent to Mertice $M$. Clark, Department of Psychology, McMaster University, Hamilton, Ontario, Canada L8S $4 \mathrm{~K} 1$. sual stimulus, rarely bite, and are relatively resistant to handling-induced seizures. The critical factor in the expression of enhanced reactivity in gerbils reared with shelter available is the opportunity to experience a place of concealment during maturation (Clark \& Galef, 1977) rather than the reduction in exposure to external stimulation provided by shelter living (Daly, 1973; Hutchings, 1968).

While the results described briefly above indicate that rearing gerbils in environments providing shelter is sufficient to induce marked enhancement of reactivity, these findings fail to provide information adequate to determine the role of shelter experience in the development of enhanced reactivity. Gottlieb (1976a, 1976b) proposed that "experience can play at least three roles in the development of behavior and the nervous system: (1) it can maintain (sustain, preserve) ongoing developmental states... (2) it can facilitate development, and (3) it can induce (channel, determine) development" (Gottlieb, 1976b, p. 28).

Experiment 1 of the present series was undertaken to examine the importance of shelter experience in the induction and maintenance of reactivity in gerbils. Experiments investigating the possible facilitating effects of shelter experience on the development of reactivity will be reported separately (Clark \& Galef, Note 1). 


\section{Experiment 1}

If shelter experience is necessary to induce development of enhanced reactivity in gerbils, then une would expect gerbils reared in environments providing shelter to be more reactive than those reared without shelter irrespective of the age at which testing was performed. If, on the other hand, shelter experience is necessary only to maintain a responsivity that develops in all gerbils independent of their rearing environment, then one would expect all young gerbils to develop reactivity to stimulation regardless of shelter experience during ontogeny. On the maintenance hypothesis, one would further expect the reactivity of shelterhoused gerbils to remain elevated and that of gerbils housed without access to shelter to wane as the animals grow older.

In the present experiment gerbils were reared and housed either in cages providing or not providing access to shelter, and independent groups were tested for response to sudden visual stimulation at six ages ranging from 26 to 181 days.

\section{Method}

Subjects. Subjects were 384 Mongolian gerbils (Meriones unguiculatus) selected from 276 litters born in the McMaster colony to females descended from stock acquired from Tumblebrook Farms (Brookfield, Mass.).

Subject assignment. Sixty-four subjects were tested in the shelter-field apparatus described below at each of six ages $(26,31,61,91,127$, and 181 days). Half of the subjects tested at each age were selected from litters reared and housed in cages providing access to shelter, and the other half from litters reared and housed in standard laboratory cages lacking shelter. Half of the subjects in each of these 12 groups ( 32 subjects/group) were treated as experimental subjects and half as control subjects in the shelter-field test described below. There were, thus, 24 groups (12 experimental and 12 control) of 16 subjects each. No more than two subjects from any litter were assigned to any single group, and each of the 24 groups was composed of eight male and eight female subjects.

Rearing and housing conditions. Multiparous female gerbils and their mates were housed in $(35 \times 30 \times$ $15 \mathrm{~cm}$ ) polypropylene cages (Maryland Plastics Inc., New York) covered with .5-in. (1.27-cm) hardware cloth. The floor of each cage was covered with a thin layer of bedding material (Betta-chip, Northeastern Products, Warrensburg, New York). The colony was maintained on ad lib food and water in a temperature-controlled colony room on a $12: 12 \mathrm{hr}$ light/dark cycle.

On the day of birth a litter was moved with its parents to a new cage either providing or lacking shelter. Each litter to be reared in the absence of shelter was placed in a cage identical to the one in which it was born; a litter to be reared in a cage providing shelter was placed in an identical cage containing a wooden box $(28 \times 17 \times 9 \mathrm{~cm})$ with a single entrance $(5 \times 5 \mathrm{~cm})$.

Subjects were left undisturbed in their home cage until the day prior to testing in the shelter-field apparatus except for removal of the male (Day 9), marking of pups by shaving (Day 16), removal of the dam (Day 35 ), and cage cleaning and renewal of markings every 2 wk from Day 16.

Twenty-four hours prior to testing, subjects were transferred in pairs from their rearing cages to holding cages identical to, and containing food and bedding from, their home cage. One hour prior to testing, the wooden shelter was removed from the holding cages of shelter-reared subjects to permit them to light adapt.

Shelter-field test apparatus. Testing was conducted in a wood-floored enclosure $(1.2 \times 1.2 \mathrm{~m})$ with sheetmetal walls $.9 \mathrm{~m}$ high. A wooden shelter $(30.5 \times 30.5 \times$ $15.2 \mathrm{~cm})$ with two entrance holes $(5 \times 5 \mathrm{~cm})$ was located in one corner of the enclosure (see Figure 1). Behavior occurring in the enclosure was monitored by closedcircuit television. At the conclusion of each subject's testing, the entire apparatus was cleaned with a moist cloth.

Testing procedure (experimental groups). At the beginning of testing, an individual subject was placed in one corner of the enclosure illustrated in Figure 1, and after the subject had made its first exit from the shelter, it was allowed at least $3 \mathrm{~min}$ to explore the enclosure. In an effort to ensure that all subjects were familiar with the location of the shelter, a subject not entering and leaving the shelter at least five times within the 3-min exploration period was left undisturbed in the enclosure until it had made five shelter exits.

Immediately following completion of the exploration period, a visual stimulus (a rubber mask of a male human face) was presented to each subject in each of the 12 experimental groups when that subject (a) was within $46 \mathrm{~cm}$ of the shelter, (b) was facing the corner of the enclosure in which the visual stimulus was to be presented, and (c) had been moving during the preceding 5 sec (Fentress, 1968a, 1968b). The test stimulus was

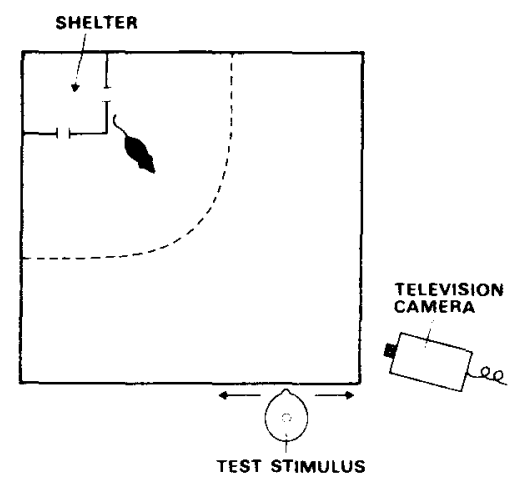

Figure 1. Overhead schematic of the 1.2-m-sq. shelter-field test apparatus. 
introduced over one corner of the enclosure, moved slowly from left to right three times, and then held in a verticle orientation. The total period of exposure of the test stimulus lasted 15 sec.

Testing procedure (control groups). Subjects in control groups were treated identically to those in experimental groups except that no visual stimulus was presented to subjects in control groups at the time it was presented to subjects in experimental groups.

Data collection. During the 2-min period following stimulus presentation (or, in the case of control subjects, nonstimulus presentation), the experimenter recorded the time required for each subject to reach shelter, the time required for each subject to first emerge from shelter, the total time spent in concealment by each subject, and the presence or absence of foot thumping. Experimental conditions were arranged so that at the time of testing, the experimenter was unaware of the environment in which a given subject had been reared.

\section{Results}

The main results of Experiment 1 are presented in Figure 2 which presents data describing the flight (2A), concealment (2B and $2 \mathrm{D}$ ), and foot-thumping (2C) behaviors of experimental and control subjects reared and housed in cages providing or lacking shelter.

Subjects that reached shelter within $3 \mathrm{sec}$ of initiation of visual stimulus presentation were considered to have "fled" in response to it. A criterion of $3 \mathrm{sec}$ to reach shelter following stimulus presentation was selected to differentiate subjects fleeing in response to stimulus presentation from those not fleeing. Less than $1 \%$ of control subjects (subjects not receiving stimulus presentation) reached shelter within $3 \mathrm{sec}$ of the onset of the test period. Thus, a 3-sec criterion successfully discriminated flight in response to stimulus presentation from random shelter entry.

As is clear from examination of Figure 2, at 26 days of age weanling gerbils, indepen-
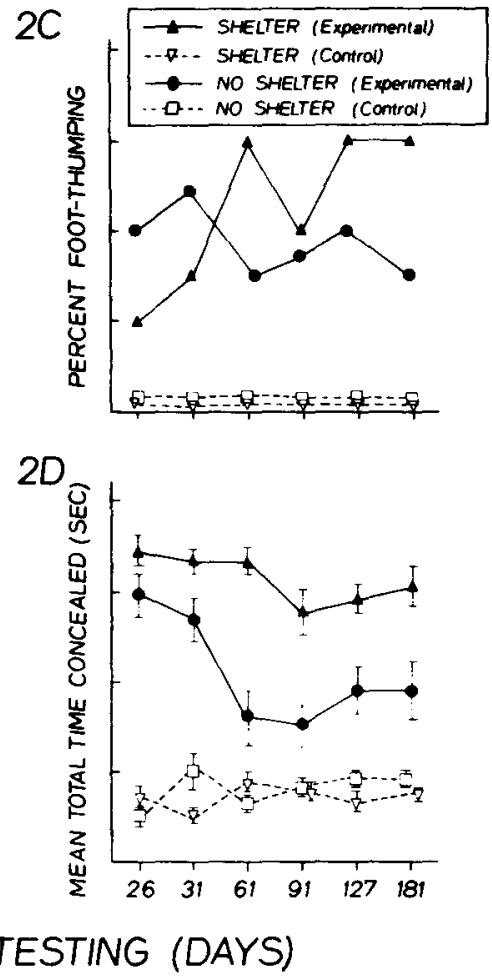

Figure 2. Behavior of experimental and control subjects in the shelter-field test at intervals between 26 and 181 days of age after housing in cages providing or lacking shelter. (A: Percentage of subjects reaching shelter within $3 \mathrm{sec}$ of stimulus presentations [fleeing]. B: Mean latency to first emerge from shelter. Flags indicate $\pm 1 S E$. C: Percentage of subjects foot thumping. D: Mean total time spent in shelter during the 120 -sec test period. Flags indicate $\pm 1 S E$.) 
dent of rearing condition, responded to presentation of the test stimulus by fleeing rapidly to the area providing concealment, remaining concealed for $80-90 \mathrm{sec}$ before first emerging from shelter, and spending $75 \%-90 \%$ of the 120 -sec test period in the sheltered area. The fact that 26-day-old control subjects did not behave in a similar fashion indicates that the behavior observed in experimental subjects was a response to presentation of the visual stimulus and not the results of exploratory patterns in young animals.

As can also be seen in Figure 2, the condition under which the subjects were reared and housed began to have an effect on response to stimulus presentation at 61 days of age and continued to do so into adulthood. Subjects housed in cages providing access to shelter continued to exhibit rapid flight to shelter, reluctance to emerge from shelter, and prolonged concealment behavior into maturity, whereas those lacking shelter in their home cages exhibited a waning of their response to stimulus presentation. As we have previously reported (Clark \& Galef, 1977), those subjects in experimental groups that failed to flee in response to stimulus presentation frequently approached and visually fixated the stimulus object. No sex differences were found in any group on any measure.

\section{Discussion}

The finding that all 26-day-old gerbils are highly reactive is not consistent with the hypothesis that shelter rearing is a necessary condition for the development of heightened reactivity (induction hypothesis). To the contrary, the data of Experiment 1 suggest that shelter experience is essential for the maintenance of a heightened reactivity that develops in all gerbils independent of the shelter provided in their rearing environment.

\section{Experiment 2}

Subjects in Experiment 1 were both housed in cages providing shelter from birth to testing and tested immediately after shelter experience. Therefore the results of
Experiment 1 do not permit determination either of the duration of the effects of shelter experience on reactivity or the range of ages during which exposure to shelter acts to maintain reactivity. The present experiment was undertaken to investigate both of these issues.

Practical considerations necessitated the use of brief exposures to shelter to explore the period during ontogeny when shelter experience is capable of influencing reactivity. The results of our previous work (Clark \& Galef, 1977, Experiment 6) indicated that even a 24-hr exposure to an environment providing shelter had marked effects on reactivity. It therefore seemed reasonable to employ $24-\mathrm{hr}$ exposure to shelter as our independent variable.

\section{Method}

Subjects. Subjects were 288 gerbils from the McMaster colony reared and housed in cages lacking access to shelter.

Procedure. Rearing conditions, group assignment, and test procedures were identical to those employed in Experiment 1. Five independent groups of 32 subjects were first reared in home cages lacking shelter for $30,60,90,126$, or 180 days, then placed with food and bedding from their home cage in a cage providing shelter for $24 \mathrm{hr}$, and then tested in the shelter-field apparatus for response to sudden visual stimulation. Two further groups ( 16 subjects/group) were employed to ensure that the results obtained in the main experiment were not solely a function of the very brief periods of exposure to shelter employed. These additional subjects were housed in home cages lacking shelter for 120 days and then transferred in pairs, with food and bedding from their home cages, to new cages. One group of 16 subjects was transferred to cages providing shelter, and one group of 16 subjects was transferred to cages lacking shelter. Subjects were left undisturbed in their new cages for $1 \mathrm{wk}$ and were tested as experimental subjects at 127 days of age.

Following the first test, all subjects to be tested a second time in the shelter-field apparatus were returned to their home cages (lacking shelter) and left undisturbed until retesting. Retesting of subjects exposed to shelter at 30 days of age was carried out at 61 days of age, and retesting of subjects exposed to shelter at 60 or 90 days of age was conducted at 127 days of age.

For the purpose of determining whether any of the effects on reactivity observed during retesting were the result of the first test experience, three additional groups (32 subjects/group) were left undisturbed in cages lacking shelter except for testing at 31 and 61 days of age, 61 and 127 days of age, or 91 and 127 days of age. Half of the subjects in each of these three groups were tested twice as experimental subjects, and half were tested twice as control subjects. 


\section{Results and Discussion}

Test 1. Figure 3 presents data describing the flight (3A), concealment (3B and $3 \mathrm{D})$, and foot thumping (3C) behavior of experimental and control subjects during their first testing at $31,61,91,127$, and 181 days of age. Data from subjects in Experiment 1 reared and housed in cages lacking access to shelter and tested at $31,61,91,127$, and 181 days of age are presented for purposes of comparison, as are data from subjects either exposed or not exposed to shelter for $1 \mathrm{wk}$ at 120 days of age and tested at 127 days of age.

Examination of Figure 3 reveals that 24-hr exposure to an environment providing shelter at 60 days of age increased reactivity during testing at 61 days of age. In comparison with experimental subjects lacking shelter experience at 60 days of age, experimental subjects exposed to shelter at 60 days of age fled more frequently (Fisher's exact probability test, $p<.005$ ), exhibited increased latency to emerge from shelter $(t=$ $2.00, p<.05)$, increased their total time spent in shelter $(t=3.18, p<.005)$, and exhibited slightly more frequent foot thumping (Fisher's exact probability test, $p<.30$ ). Neither 24-hr exposure to shelter at 30,90 , 126 , or 180 days of age nor 7-days exposure to shelter at 120 days had any measurable effect on behavior in the test situation.

The above results suggest that 60 -day-old gerbils are sensitive to a $24-\mathrm{hr}$ experience with shelter but that older and younger gerbils are not. The present data are not, however, sufficient to eliminate a number of alternative explanations of the apparent
$3 A$

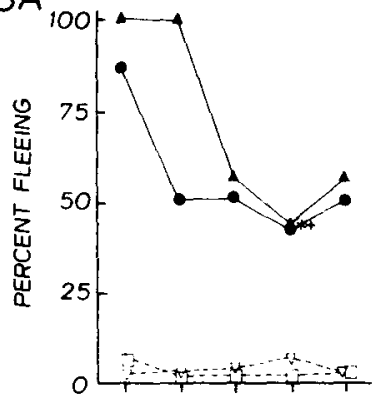

$3 B$

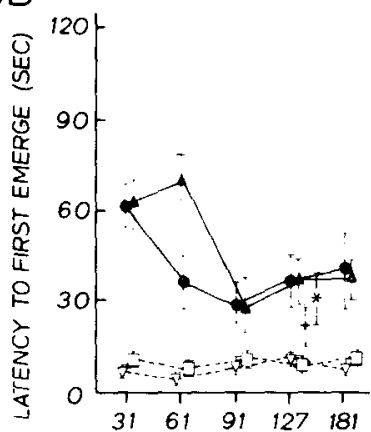

$3 C$

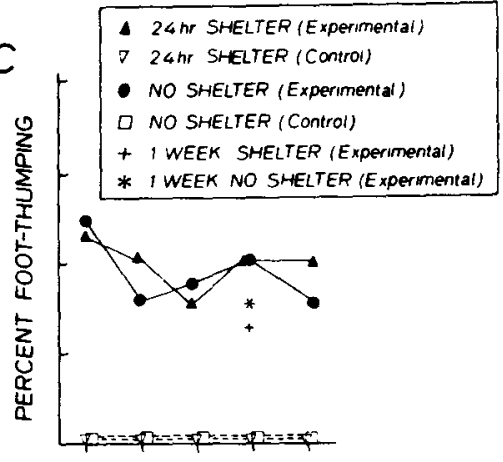

$3 D$

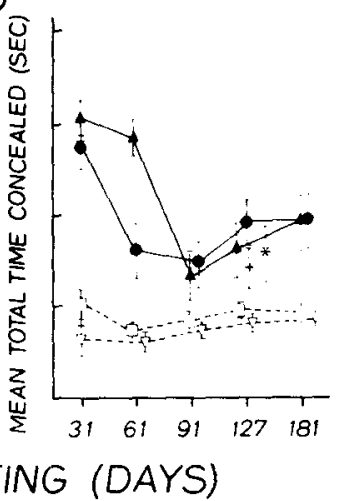

Figure 3. Behavior of subjects in Experiment 2 exposed to shelter for 24 hr or for 1 wh immediately prior to testing in the shelter-field enclosure. (Data from experimental subjects housed in cages lacking access to shelter in Experiment 1 are presented for purposes of comparison. A: Percentage of subjects reaching shelter in less than $3 \mathrm{sec}$ following stimulus presentation [fleeing]. B: Mean latency to first emerge from shelter. Flags indicate $\pm 1 S E$. C: Percentage of subjects foot thumping. D: Mean total time spent in shelter during the $120-\sec$ test period. Flags indicate $\pm 1 S E$.) 
limitation of sensitivity to experience with shelter to a period around 60 days of age.

First, subjects in Test 1 not only were exposed to shelter at different ages but also were tested at different ages. It is at least possible that the observed differences in reactivity in the test situation among subjects exposed to shelter at varying ages reflects differences in probability of responding as a function of age at testing. The results of Test 2 , described below, in which subjects exposed to environments providing shelter for $24 \mathrm{hr}$ at 60 and 90 days of age and retested at 127 days of age provide a definitive test of the effects of age of exposure and age of testing on responsivity.
Second, the failure to find effects of exposure to shelter at 30 days of age in pups tested at 31 days of age may have reflected the fact that even pups lacking shelter exposure invariably respond vigorously to stimulus presentation when they are 31 days old. Thus a ceiling effect would obscure any influence of shelter exposure on pups 30 days old tested at 31 days of age. Data from pups exposed to shelter at 30 days and retested at 61 days of age should clarify the effects of shelter experience on reactivity.

'Test 2. The main results of the second test of subjects exposed to shelter for $24 \mathrm{hr}$ at 30 days of age and retested at 61 days of

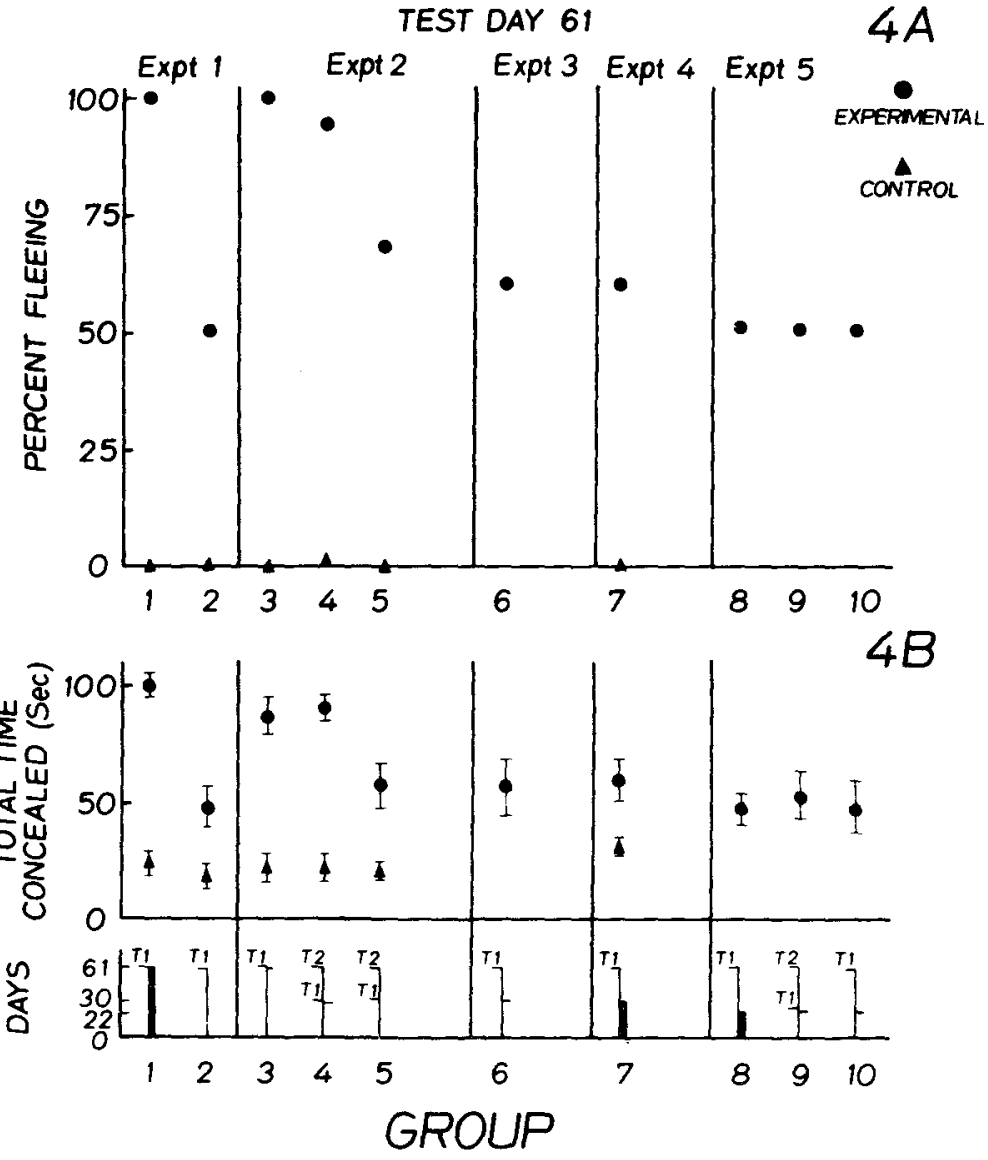

Figure 4. Behavior of experimental and control subjects tested at 61 days of age in the shelter-field apparatus in Experiments 1-5. (A: Percentage of subjects reaching shelter within 3 sec of stimulus presentation [fleeing]. B: Mean total time spent in concealment during the 120 -sec test period. Flags indicate $\pm 1 S E$. Each schematic along the abscissa describes the treatment of the group directly above it. Excursions to the right of the vertical indicate days spent in cages providing access to shelter; excursions to the left of the vertical indicate a test experience. $\mathrm{T} 1=$ first test, $\mathrm{T} 2=$ second test.) 
age are presented as Group 4 in Figures $4 \mathrm{~A}$ and $4 \mathrm{~B}$. The main results of the second test of subjects exposed to shelter for $24 \mathrm{hr}$ at 60 and 90 days of age and retested at 127 days of age are presented as Groups 3 and 4 in Figures 5A and 5B. In the interest of brevity, only two measures of response (percentage of subjects fleeing and mean total time spent in shelter) are shown. Data describing the mean latency to first emerge from shelter and the percentage of subjects foot thumping support the conclusions reached below, but they are not discussed further.

Inspection of Figures $4 \mathrm{~A}$ and $4 \mathrm{~B}$ reveals that subjects exposed to shelter for $24 \mathrm{hr}$ at 30 days of age, tested at 31 days of age, and retested at 61 days of age (Group 4) exhibited enhanced reactivity during retesting. In contrast, subjects not exposed to shelter, tested at 31 days of age, and retested at 61 days of age (Group 5) did not exhibit significantly enhanced reactivity during retesting. Taken together with the results of Test 1 , the
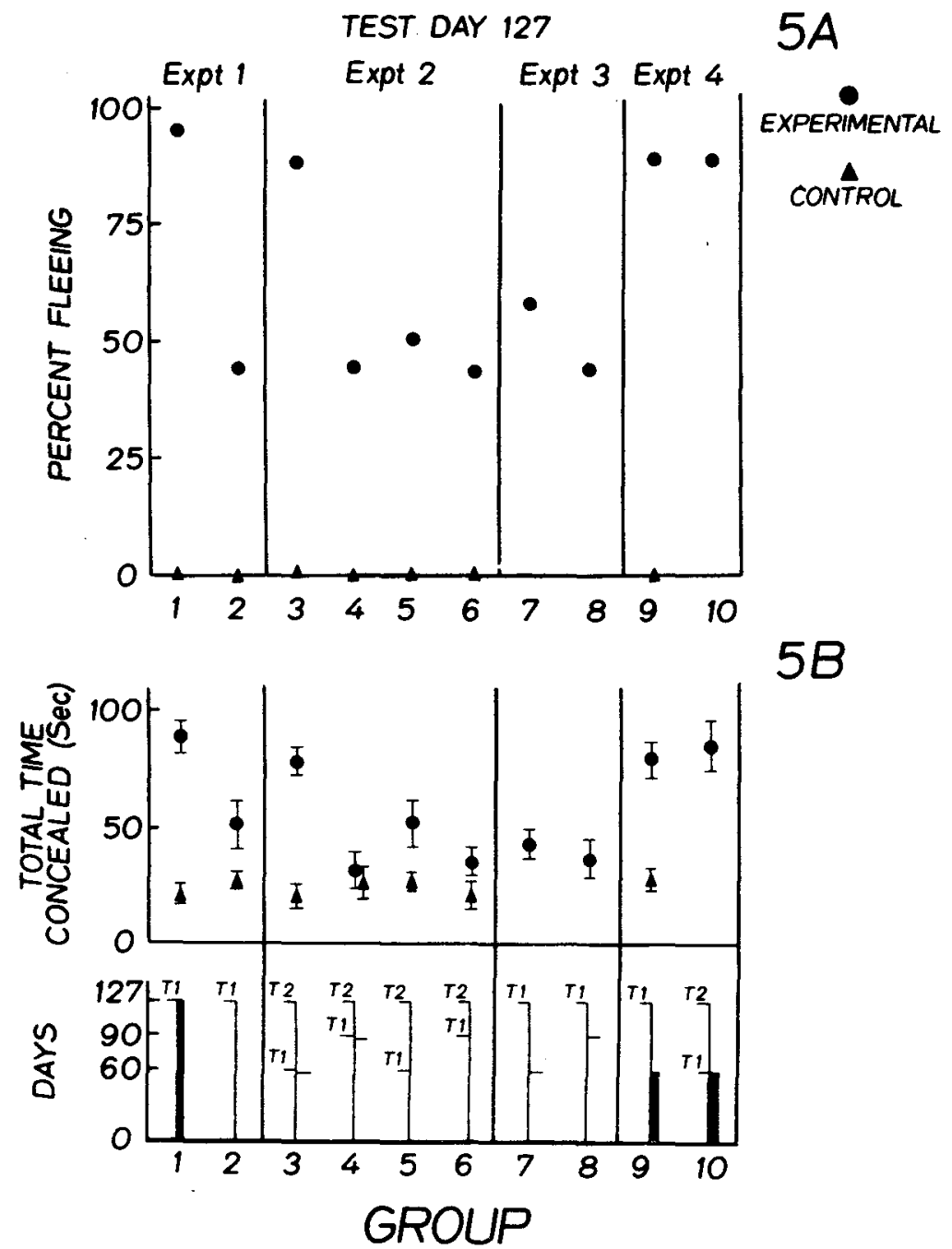

Figure 5. Behavior of experimental and control subjects tested at 127 days of age in the shelter-field apparatus in Experiments 1-5. (A: Percentage of subjects reaching shelter within 3 sec of stimulus presentation [fleeing]. B: Mean total time spent in concealment during the 120 -sec test period. Flags indicate $\pm 1 S E$. See Figure 4 caption for interpretation of schematics along the abscissa.) 
results of Test 2 indicate that the failure to find effects of shelter experience at 30 days in subjects tested at 31 days of age was, in fact, due to a ceiling effect and not to the failure of shelter experience at 30 days of age to affect maintenance of reactivity.

The data presented in Figures $5 \mathrm{~A}$ and $5 \mathrm{~B}$ clearly show that 24 -hr exposure to shelter at 60 days of age, followed by testing at 61 days of age, is effective in maintaining reactivity during retesting at 127 days of age (Group 3) but that 24-hr exposure to shelter at 90 days of age, followed by testing at 91 days of age, (Group 4) is not. These data clearly suggest the existence of a sensitive period for susceptibility to shelter experience which wanes prior to 90 days of age. The failure to find effects of testing at 61 days of age on retesting at 127 days of age (Figures $5 \mathrm{~A}$ and $5 \mathrm{~B}$, Group 5) indicates, in addition, that testing experience at 61 days of age is not sufficient to maintain reactivity at 127 days of age.

Although the behavior of subjects continuously housed with shelter available until 61 days of age was not discriminable from that of subjects exposed to shelter for $24 \mathrm{hr}$ at 60 days of age when tested at 61 days of age in the shelter-field test apparatus, other observations suggest that continuous housing with shelter was more effective in maintaining reactivity than was brief exposure to shelter; for example, whereas 14 of 32 gerbils housed continuously with shelter exhibited epileptiform seizures when placed on a visual cliff at 68 days of age, only 5 of 32 gerbils exposed to shelter for $24 \mathrm{hr}$ at 60 days of age did so. Thus, brief exposure to shelter maintains a portion but not all of the responsive phenotype.

\section{Experiment 3}

The results of 'Test 2 in Experiment 2 indicate that 24 -hr exposure to shelter at either 30 or 60 days of age is necessary to maintain reactivity for a month or more. However, the possibility remains that shelter exposure alone is not sufficient to do so. In the present experiment, all subjects exhibiting enhanced reactivity in Test 2 had been exposed both to shelter and to Test 1 . It is possible that the combination of shelter ex- perience and testing was necessary for maintenance of reactivity over extended periods. The present experiment was undertaken to determine the sufficiency of brief shelter experience to maintain reactivity for extended periods. Three independent groups of subjects were exposed to shelter at 30,60 , and 90 days of age and then tested at, respectively, 61,127 , and 127 days of age in the absence of previous testing.

\section{Method}

Subjects. Subjects were 48 Mongolian gerbil pups reared and housed in cages providing no access to shelter.

Procedures. Rearing, housing, group assignment, and testing procedures were the same as those described in Experiment 1. Three independent groups of subjects ( $n=16 /$ group) were exposed to an environment providing shelter for $24 \mathrm{hr}$ at 30,60 , or 90 days of age. Subjects exposed to shelter at 30 days of age were first tested in the shelter-field enclosure at 61 days of age, and subjects exposed to shelter at 60 and 90 days of age were first tested in the shelter-field enclosure at 127 days of age.

\section{Results and Discussion}

The main results of the testing of subjects exposed to shelter at 30 days of age and tested for response to stimulus presentation for the first time at 61 days of age are presented as Group 6 in Figures $4 \mathrm{~A}$ and $4 \mathrm{~B}$. The main results of subjects exposed to shelter for $24 \mathrm{hr}$ at 60 and 90 days of age and tested for the first time at 127 days of age are presented as Groups 7 and 8 in Figures 5A and $5 \mathrm{~B}$. As before, in the interest of brevity, data describing time to first emergence from shelter and to foot thumping have been omitted from discussion. These data again support the general line of argument developed below.

Comparison of the data of the groups in the present experiment with those of appropriate groups in Experiment 2 (i.e., Figure 4, Group 4; Figure 5, Groups 3 and 4) reveals a significant decrement in response in groups exposed to shelter for $24 \mathrm{hr}$ at 30 and 60 days of age in comparison with those exposed to shelter at 30 and 60 days of age and tested immediately thereafter.

We concluded, on the basis of the main findings of Experiments 2 and 3, that although shelter experience at 60 days of age 
is sufficient to maintain reactivity (Figure 4, Group 3) this reactivity wanes rapidly (Figure 5, Group 5) unless reinforced by testing after shelter experience (Figure 5, Group 3). Similarly, subjects exposed to shelter for 24 hr at 30 days of age (Figure 4, Group 6) exhibited a waning of response to the test stimulus unless such experience was followed by testing (Figure 4, Group 4).

\section{Experiment 4}

It cannot be inferred from the fact that brief exposure to shelter is insufficient to potentiate reactivity in the test situation after a delay of several weeks, that more prolonged periods of shelter experience would not be sufficient to do so. In the present experiment, we examine the effects of long periods of exposure to an environment providing access to shelter on later response to sudden visual stimulation. Two independent groups of subjects were reared and housed in environments providing shelter from birth to either 31 or 61 days of age and tested, respectively, 1 or 2 mo later for response to visual stimulation.

\section{Method}

Subjects. Subjects were 80 gerbils from the McMaster colony.

Procedure. The general procedures were identical to those of Experiment 1 except that in the present experiment (a) 32 pups were left in cages providing shelter for 31 days, then placed in cages lacking shelter for 30 days, and tested at 61 days of age and (b) 32 pups were left in cages providing shelter for 61 days, then placed in cages lacking shelter for 66 days, and tested at 127 days of age. Half of the animals in each group were tested as experimental subjects and half as control subjects in the shelter-field test apparatus. (c) Sixteen pups were left in cages providing shelter for 60 days, tested on Day 61, housed in cages lacking shelter from Days 61 to 126, and retested in the shelter-field apparatus at 127 days of age. All pups in this last group were tested as experimental subjects in the shelter-field apparatus.

\section{Results and Discussion}

The main results of Experiment 4 are presented as Group 7 in Figures $4 \mathrm{~A}$ and $4 \mathrm{~B}$ and as Groups 9 and 10 in Figures $5 \mathrm{~A}$ and 5B. As is evident from examination of Figures 4 and 5, 31-days exposure to an environment providing shelter is not sufficient to maintain reactivity to 61 days of age (Figure 4, Group 7), but exposure to shelter for 61 days is sufficient to maintain reactivity for more than 2 mo (Figure 5, Group 9). Taken together with the results of Experiment 3 (Figure 5, Group 7), the data indicate that extended exposure to shelter is sufficient to maintain reactivity for a 2 -mo period but that a brief exposure to shelter is not.

\section{Experiment 5}

The results of Experiment 2, 3, and 4 suggest the existence of a sensitive period, ending sometime between 60 and 90 days of age, during which gerbils respond to certain experiences by exhibiting enhanced reactivity to stimulation. In the present experiment, we examine the age of onset of this period of sensitivity.

There are several constraints on such a study which determined many of the parameters that we used. First, the eyes of gerbil pups open when the young are from 16 to 21 days of age ( $M=18.2$ days), and it is highly unlikely that shelter availability would influence behavior prior to eye opening. Second, the results of Experiment 2 indicate that gerbils are sensitive to shelter experience and testing by the time they attain an age of 30 days. Third, the effects of shelter experience are not apparent in pups tested before they reach 61 days of age (Experiments 1 and 2). Thus, the search for a time of onset of sensitivity to shelter experience is restricted to a period from 22 to 29 days of age, and testing for the effects of shelter experience cannot reasonably be undertaken until pups are 61 days of age. Given the practical constraints, we decided to examine the effects of shelter experience at the earliest possible age ( 21 days) on reactivity at 61 days of age.

\section{Method}

Subjects. Subjects were 48 Mongolian gerbils from the McMaster colony. All subjects were treated as experimental subjects in the test situation.

Procedure. Rearing, housing, group assignment, and testing procedures were the same as those described in Experiment 1. Independent groups of gerbil pups ( $n$ $=16 /$ group) were (a) reared in an environment providing shelter from birth to 22 days of age and tested at 61 days of age, (b) exposed to shelter for $24 \mathrm{hr}$ at 21 days 
of age and tested first at 22 and then at 61 days of age, or (c) exposed to shelter for $24 \mathrm{hr}$ at 21 days of age and tested at 61 days of age.

\section{Results and Discussion}

The main results of Experiment 6 are presented in Groups 8, 9, and 10 in Figures $4 \mathrm{~A}$ and $4 \mathrm{~B}$. As is clear from examination of the figures, neither 24-hr exposure to shelter at 21 days of age and testing at 22 days of age nor exposure to shelter from birth to 22 days of age is sufficient to potentiate responsivity during testing at 61 days of age. Comparison of the behavior of subjects in Group 9 of Figures $4 \mathrm{~A}$ and $4 \mathrm{~B}$ with that of subjects in Group 4 , in the same figures, reveals a marked difference in the effects of 24-hr shelter experience and testing at 30 and 21 days of age. Experience at the former age is sufficient to potentiate reactivity during testing at 61 days, but experience at the latter age is not. These data are consistent with the hypothesis that the period of sensitivity to experience of shelter and testing begins sometime between 21 and 30 days of age.

\section{General Discussion}

The results of the present series of studies provide considerable clarification of the role of the rearing and housing environment in the development of reactivity in domesticated gerbils.

First, it is clear that experience of an environment providing access to shelter is not a necessary condition for the development of the reactive phenotype. All gerbils, both those exposed to an environment providing shelter during ontogeny and those not so exposed, are highly reactive at 26 and 31 days of age.

Second, the data indicate that exposure to an environment providing shelter is a necessary condition for the prevention of waning of reactivity. Gerbils housed in environments providing continuous access to shelter remain reactive for 6 mo or more, whereas those lacking access to shelter show considerable reduction in response to stimulation by the time they reach 2 mo of age.

Third, our data suggest that gerbils are not equally responsive to the effects of shelter exposure throughout life. Twenty-four hours of exposure to an environment providing shelter at 60 days of age is sufficient to potentiate reactivity in an immediately subsequent test, but neither 24-hr exposure to shelter at 90 days of age nor 7-days exposure to shelter at 127 days of age has a similar effect.

Fourth, during a restricted period in ontogeny the combination of exposure to shelter and testing has prolonged effects on reactivity. Gerbils 30 and 60 days of age exposed to shelter and then tested exhibit high levels of reactivity during a second test 1 and 2 mo later. Gerbils receiving similar experiences at 21 or 90 days of age do not exhibit enhanced reactivity when retested approximately 1 mo following exposure and initial testing.

The laboratory experiences both of rearing with shelter available and of flight to shelter in response to sudden stimulation have obvious parallels in the natural world. Wild gerbils are known to live in burrow systems and have been reported to flee into them when approached either by their natural predators (foxes, polecats, kites, etc.; Leont'ev, 1954, 1962; Won, 1961) or by humans (Thomas, 1908). It seems reasonable to propose that such experiences may play an important role in the development of the wariness that typifies the behavior of gerbil populations in natural or seminatural habitats (Thiessen \& Yahr, 1977; Thomas, 1908). We have previously discussed evidence suggesting that many of the differences in behavior between wild and domesticated populations of gerbils may reflect differences in the physical environment in which members of these populations are reared (Clark $\&$ Galef, 1977). The results of the present series of experiments indicate that the docility and tameness to be observed in laboratory gerbils are, at least in part, the result of a failure to experience shelter during the period when such experience is a necessary condition for the maintenance of a reactive phenotype that develops in all gerbils independent of shelter experience.

\section{Reference Note}

1. Clark, M. M., \& Galef, B. G., Jr. Visual experience: A factor in the onset of emotionality in the Mongolian gerbil. Manuscript in preparation, 1978. 


\section{References}

Clark, M. M. The effects of the physical environment during maturation on subsequent reactivity to visual stimulation in Mongolian gerbils (Meriones unguiculatus). Unpublished doctoral dissertation, McMaster University, Hamilton, Canada, 1974.

Clark, M. M., \& Galef, B. G., Jr. The role of the physical rearing environment in the domestication of the Mongolian gerbil (Meriones unguiculatus). Animal Behaviour, 1977, 25, 298-316.

Daly, M. Early stimulation of rodents: A critical review of present interpretations. British Journal of Psychology, 1973, 64, 435-460.

Fentress, J. C. Interrupted ongoing behaviour in two species of vole (Microtus agrestis and Cethrionomys britannicus): I. Response as a function of preceding activity and the context of an apparently "irrelevant" motor pattern. Animal Behaviour, 1968, 16, 135153. (a)

Fentress, J. C. Interrupted ongoing behaviour in two species of vole (Microtus agrestis and Clethrionomys britannicus): II. Extended analysis of motivational variables underlying fleeing and grooming behaviour. Animal Behaviour, 1968, 16, 154-167. (b)

Gottlieb, G. Conceptions of prenatal development: Behavioral embryology. Psychological Review, 1976, 83, 215-234. (a)

Gottlieb, G. The roles of experience in the development of behavior and the nervous system. In G. Gottlieb (Ed.), Studies on the development of behavior and the nervous system: Vol.3. Neural and behavioral specificity, New York: Academic Press, 1976. (b)

Hamaganov, S. A. K biologii kogtistoi peschanki v rajone Torejskikh ozer. Izvestiya Irkutskogo gosudarstvennyi nauchno-issledovatel'skogo protivochumnogo instituta Sibiri i Dal'nego Vostoka,
$1954,12,150-155$.

Hutchings, D. E. Infantile handling and body temperature change in the rat: II. Parametric investigations of body temperature loss and theoretical implications. Transactions of the New York Academy of Sciences, 1968, 30, 992-1000.

Leont'ev, A. N. K ekologii kogtistoi peschanki v By ryat-Mongol'skoi ASS. Izvestiva Irkutskogo gosudarstuennyi nauchno-issledovatel skogo protioochumnogo instituta Sibiri i Dal'nego Vostoka. $1954,12,137-149$

Leont'ev, A. N. K sutochnoi aktivnosti mongolskoi peschanki i polevki Brandta. Izvestiya Irkutskogo gosudarstvennyi nauchno-issledovatel'skogo protivochumnogo instituta Sibiri i Dal'nego Vostoka, $1957,16,78-84$.

Leont'ev, A. N. K izucheniyu populyatsii mongol'skikh peschanok metodom mecheniya. Izvestiya Irkutskogo gosudarstvennyi nauchno-issledovatel'skogo protivochumnogo instituta Sibiri i Dal'nego Vostoka, 1962, 24, 296-302.

Tanimoto, K. Ecological studies on plague-carrying animals in Manchuria, Part III. Dobutsugaku Zasshi, 1943, 55, 117-127.

Thiessen, D. Footholds for survival. American Scientist, 1973, 61, 346-351.

Thiessen, D., \& Yahr, P. The gerbil in behavioral investigations. Austin: University of Texas Press, 1977.

Thomas, O. The Duke of Bedford's zoological exploration in eastern Asia: IX. List of mammals from the Mongolian plateau. Proceedings of the Zoological Society of London, 1908, 104-110.

Won, P. H. Studies on the ecological observation of rodentia in Manchuria and Korea. Part II. Seoul, Korea: Zoological Institute, Dong Kook University, 1961.

Received April 10, 1978 